\title{
EM BUSCA DA COOPERAÇÃO NA GESTÃO SOCIAL: EVIDÊNCIAS DE UMA CATEGORIA POSTA À
} COORDENAÇÃ̃ DE LÓGICAS E ESPAÇOS HÍBRIDOS DO TERCEIRO SETOR

\author{
Valderí de Castro Alcântara \\ Doutorando em Administração \\ Universidade Federal de Lavras \\ Lavras - Minas Gerais - Brasil \\ valderidecastroalcantara@gmail.com \\ Eloisa Helena de Souza Cabral \\ Doutor em Ciências Sociais \\ Universidade Federal de Lavras \\ Lavras - Minas Gerais - Brasil \\ elocabral@uol.com.br \\ Paulo de Tarso Muzy \\ Doutor em Física Teórica \\ Universidade de São Paulo \\ São Paulo - São Paulo - Brasil \\ ptmuzy@uol.com.br \\ Laís Costa de Oliveira \\ Bacharel em Administração Pública \\ Universidade Federal de Lavras \\ Lavras - Minas Gerais - Brasil \\ laiscosta_oliveira@hotmail.com
}

\section{RESUMO}

O objetivo deste ensaio é problematizar como a "cooperação" se estabelece como uma categoria teórico-empírica necessária à coordenação de lógicas e espaços híbridos no campo de práticas e teorias da gestão social. Desenvolvemos três argumentos: (a) Na perspectiva da gestão social, a cooperação é uma categoria importante para a coordenação de espaços e lógicas híbridas; (b) Um campo científico e social, marcado pelo hibridismo, demanda normativamente o elemento da cooperação nas suas interrelações; e, (c) A cooperação é essencial em três momentos que se articulam: (1) entre os acadêmicos e os saberes híbridos, tendo em vista o desenvolvimento de um campo científico que valora a cooperação, (2) entre os praticantes dada a ênfase da gestão social enquanto prática gerencial e (3) entre acadêmicos e praticantes. A "cooperação" se estabelece como uma categoria teórico-empírica e pode ser considerada como um mecanismo de coordenação entre as lógicas que se apresentam no espaço híbrido, no qual atuam as organizações do terceiro setor e no campo interdisciplinar da gestão social que também se constitui híbrido pelas suas raízes práticas e evidências empíricas. Foi mostrado ainda que o hibridismo não é elemento que desfigura a "identidade" do gestor social, mas, pelo contrário, que o molda e o torna capaz de coordenar no espaço intermediário as diferentes lógicas e suas tensões. A própria ideia de cooperação gera tensões, sendo preciso reconhecer que a noção que defendemos não é "purificada" ou "idealizada", devendo estar sempre aberta a discussão e experimentação empírica dos valores-fatos a ela relacionados.

Palavras-chave: Cooperação; Hibridismo; Interdisciplinaridade; Tensões; Terceiro setor.

\section{PERSUING COOPERATION IN SOCIAL MANAGEMENT: EVIDENCE OF A CATEGORY RELATED TO THE COORDINATION OF LOGICS AND HYBRID SPACES OF THE THIRD SECTOR}

\begin{abstract}
The purpose of this essay is to study how "cooperation" is established as a theoretical-empirical category necessary to the coordination of hybrid logics and spaces in the field of social management practices and theories. Thus, we developed three arguments: (a) From the perspective of social management, cooperation is an important category for the coordination of hybrid spaces and logics; (b) A scientific and social field marked by hybridism normatively demands the element of cooperation in its inter-relationships; and (c) Cooperation is essential in three moments that are articulated: (1) between academics and hybrid knowledge in order to develop a scientific field which values cooperation, (2) among practitioners for the emphasis of the social management as managerial practice and (3) between academics and practitioners. . A "cooperação" se estabelece como uma categoria teórico-empírica e pode ser considerada como um mecanismo de coordenação entre as lógicas que se apresentam no espaço híbrido, no qual atuam as organizações do terceiro setor e no campo interdisciplinar gestão social - que também se constitui híbrido pelas suas raízes práticas e evidências empíricas. Cooperation is established as a theoretical-empirical category and can be considered as a mechanism of coordination between the logics that present themselves in the hybrid zone in which third sector organizations act and in the field of interdisciplinary social management. This field is also hybrid for practical roots and empirical evidence. The results shown that hybridity is not an element that disfigures the "identity" of the social manager but shapes it and makes it capable of coordinating the different logics and their tensions in the intermediary zone. The very idea of cooperation generates tensions, so the concept that we defend is not "purified" or "idealized", and the discussion and empirical experimentation of the facts-values related to this subject must always be open.
\end{abstract}

Key words: Cooperation; Hybridism; Interdisciplinary; Tensions; Third sector. 


\section{INTRODUÇÃO}

Pesquisas no campo da gestão social encontram-se em ampliação de suas bases teóricas, metodológicas, experiências empíricas e institucionalização de cursos e eventos (Cançado, 2011; Araújo, 2012; Menon, 2016). No entanto, Guerra (2015, p. 14) indica que "[...] existem importantes debates e divergências acerca de sua constituição e natureza". São marcantes diferentes entendimentos e dilemas da gestão social como: uma área em busca de consolidação como campo de conhecimento científico - com a formação do primeiro paradigma (Cançado, 2011); a existência de consistências e inconsistências (Araújo, 2012); multiparadigmática e de natureza interdisciplinar (Fischer et al., 2006) e ainda um campo de natureza híbrida (Guerra \& Teodósio, 2014). É sobre essa "natureza" híbrida do campo de pesquisas e práticas da gestão social que este artigo pretende contribuir. Coerente com isso, discutimos também a questão da interdisciplinaridade (Fischer et al., 2006) a partir da cooperação entre diferentes perspectivas epistêmicas na gestão social (Alcântara, 2015; Alcântara \& Pereira, 2017).

Recentemente, Guerra e Teodósio (2015, p. 47) colocaram que o campo da gestão social está sendo formado por "múltiplos saberes, definições e práticas" que não se limitam a um conceito único - Justen, Moretto Neto e Garrido (2014) também argumentam contra uma visão monocular da gestão social. Essa questão aparece também em outros trabalhos, tais como Fischer et al. (2006), Boulossa e Schommer (2008) e Araújo (2012). Assim, a convergência teórica acerca da heterogeneidade, da multiplicidade e da diversidade como fatores determinantes para o conceito de gestão social e sua raiz prática, nos convidam a considerar evidências dos campos aos quais ela se aplica, para compor o conceito, como é o caso do terceiro setor.

Cabral $(2008 ; 2011$ a) busca construir uma visão relacional com dualidades e tensões para o conceito de gestão social e, para tanto, examina as especificidades institucionais do terceiro setor a despeito do afastamento de diversos autores do campo da gestão social do estudo desse ambiente, tais como Tenório (2005), Cançado, Tenório e Pereira (2011) e Cançado, Pereira e Tenório (2015), dentre outros. Nesse momento, é suficiente indicarmos que os textos de Cabral (2008; 2011a; 2011b) concebem o terceiro setor como um espaço intermediário onde as instituições, as normas e as pessoas compartilham diferentes lógicas advindas do Estado, do mercado e das comunidades, portanto, um espaço plural, híbrido e relacional.

A abordagem de Cabral (2011a) se inspira principalmente no welfare mix de Evers (1995) e encontra respaldo no trabalho recente de Aimers e Walker (2016) ao discutirem organizações do terceiro setor pela lente do hibridismo de lógicas advindas de múltiplos setores. Embora a contribuição de Evers (1995) se refira a países europeus, para os quais o Welfare State é uma realidade, interessa à abordagem de Cabral (2011a), o caráter de mistura, de hibridismo, de diversidade, capturado por Evers e que ofereceu as bases para pensar as organizações do terceiro setor brasileiras (Cabral, 2008; 2011a). De Evers (1995) também se apreende a noção de que no espaço do terceiro setor diferentes racionalidades e discursos coexistem. Alves (2002, p. 47), ao tratar da visão deste autor no Brasil, afirma que ela é potencialmente interessante e permite "[...] que o fenômeno seja analisado sob uma perspectiva multidisciplinar".

Colocado isso, emerge nossa problemática: em espaços sociais híbridos, plurais e permeados por diversas lógicas, os conflitos e dissensos podem ser potencializados e impactarem na permanência do "contrato" que une as pessoas (e suas diferentes expectativas, necessidades, capacidades, interesses e representações) em torno de objetivos comuns. Diante disso, a cooperação se torna fundamental na coordenação e gestão destes espaços/lógicas. Por sua vez, o entendimento do campo da gestão social como híbrido demanda conhecimentos interdisciplinares e a cooperação entre diferentes perspectivas para uma apreensão de seus campos de estudo e prática. Dessa maneira, pluralidade, hibridismo e cooperação são visões relevantes tanto aos praticantes quanto aos acadêmicos da gestão social.

Estas questões (que levantam as noções de pluralidade, hibridismo, tensões, etc.) perpassam, como pano de fundo, a problematização de dicotomias reproduzidas no campo da gestão social, 
como entre racionalidade estratégica/instrumental e racionalidade comunicativa (e às vezes entre instrumental e substantiva), que culminam na contraposição teórica entre gestão social e gestão estratégica, a qual não se mantém no plano ontológico da vida social. A dicotomia é um processo de "purificação" das relações sociomateriais entre diferentes racionalidades, sujeitos, práticas e instituições. Conforme destaca Richard Rorty (2005, p. 119), ao tratar de uso estratégico (ação estratégica) e não-estratégico da linguagem (ação comunicativa): “A maior parte do tempo, estamos aí pelo meio entre esses dois extremo"”.

As concepções "purificadas" (dicotômicas) acabam por direcionar processos de construção do conhecimento, concepções epistemo-metodológicas, que já se pautam pela possibilidade, $a$ priori, e não problematizada de "identificar" e "separar" (dicotomicamente) ações, racionalidades e lógicas, reduzindo os potenciais de compreensão de ações, organizações, espaços e lógicas híbridas. De outra forma, este tipo de construção teórica reduz as possibilidades de hibridismo, vinculação, entanglement e tensão, antes mesmo da pesquisa de campo. A partir disso, outras dicotomias reproduzidas por pesquisadores no campo da gestão social e que podem ser problematizadas são: natural e social/cultural, fato e valor, razão e emoção, normativo e descritivo, público e privado, dentre outras dicotomias cujos nossos estudos direcionam para a existência de redes, elementos e práticas heterogêneas e híbridas.

Assim, apontamos possibilidades de estudos no campo da gestão social na direção das discussões sobre hibridismo, processos de hibridação, tensões e diferentes lógicas que, por sua vez, abre possibilidades também para pesquisas empíricas sobre cooperação entre diferentes elementos (específicos, típicos, plurais, múltiplos, distintos, divergentes, etc.). Este debate leva também a outro sobre a falta de problematização e pesquisas no campo da gestão social guiados pela categoria teórico-empírica "cooperação". No campo da gestão social, existem diversas categorias representativas, por exemplo, Cançado, Pereira e Tenório (2015) sintetizam como centrais: democracia deliberativa, dialogicidade, emancipação, esfera pública, interesse bem-compreendido, intersubjetividade, racionalidade, solidariedade e sustentabilidade. Por isso, indicamos uma das lacunas de pesquisa: apesar de evidente para um campo que se pauta nas discussões apresentadas, a cooperação não aparece como uma categoria teórica.

O objetivo central deste ensaio é problematizar como a "cooperação" se estabelece como uma categoria teórico-empírica necessária à coordenação de lógicas e espaços híbridos no campo de práticas e teorias da gestão social. Metodologicamente, este artigo é caracterizado como um ensaio teórico (Cf. Meneghetti, 2011). Segundo Meneghetti (2011, p. 345), o ensaio é uma forma de produção acadêmica mais livre e caracterizada pela possibilidade de reflexões mais abertas e busca “[...] relevância temática, rigor argumentativo elaborado, conteúdo e forma validados". Mesmo sendo um ensaio, foi realizado um procedimento de revisão bibliográfica para identificar como a cooperação é discutida pelos estudos em gestão social.

Para organizar os textos, optamos por artigos científicos publicados em periódicos e indexados nas seguintes bases: Scientific Electronic Library Online (SciELO Brasil) e Scientific Periodicals Electronic Library (Spell). Assim, no SciELO Brasil, encontramos, inicialmente, 35 artigos e, na Spell, 127 artigos. No total de 162 artigos. Nessa pesquisa, encontramos os seguintes textos que discutem, de forma mais ampla, a cooperação na gestão social: Dias e Souza (2014), Pereira, Cabral e Pereira (2015), Lampert e Sausen (2008), Ullrich e Carrion (2015) e Villela e Pinto (2009). Mesmo assim, nem todos apresentam as bases epistemológicas, elementos de práticas e consequências teóricas da categoria "cooperação" para a gestão social. Além destes, somente a tese de Guerra (2015), que identificamos de forma não sistemática, trata de forma mais densa, da cooperação. Os procedimentos destacados visaram oferecer maior sistematização ao estudo, mesmo que ele seja essencialmente um ensaio teórico. 


\section{GESTÃO SOCIAL: A CONSTRUÇÃO DE UM CAMPO HÍBRIDO}

Os trabalhos acadêmicos em gestão social envolvem artigos científicos, livros, teses e outros materiais bibliográficos que são produzidos em diferenciadas instituições de ensino, com diferentes abordagens teóricas e estudos empíricos (Cançado, 2011; Araújo, 2012; Alcântara, 2015; Guerra, 2015; Menon, 2016; Persson, 2016). A institucionalização do campo se destaca pela existência de congressos científicos, periódicos e cursos (Cançado, 2011; Araújo, 2012). Para Araújo (2012), o processo de institucionalização ocorreu de forma muito precoce. Há divergência já que Cançado, Pereira e Tenório (2015) discordam disso.

Além dessa questão, existem outras controvérsias no campo relacionados a alguns temas, tais como paradigma versus campo, paradigmático versus multiparadigmático, disciplinar versus interdisciplinar, científico versus ideológico, dentre outras (Cf. Tenório, 2005; Cançado, 2011; Araújo, 2012; Alcântara, 2015; Cançado, Pereira \& Tenório, 2015; Guerra, 2015; Menon, 2016). A título de outro exemplo das controvérsias, Araújo (2012) defende a concepção da gestão social como campo interdisciplinar, polissêmico e em construção (in progress): "[...] se trata de um campo de conhecimentos em construção em estágio ainda preliminar no qual prevalece o caráter multidisciplinar, tendendo a interdisciplinaridade" (Araújo, 2012, p. 225). Por sua vez, Cançado (2011) e Cançado, Pereira e Tenório (2015) defendem que a gestão social já alcançou muito progresso e possui um corpo teórico consistente se aproximando do seu primeiro paradigma "[...] com fundamentos teóricos específicos" (Cançado, 2011, p. 19).

No processo de desenvolvimento teórico, os pesquisadores do campo da gestão social buscaram discutir diversos temas (Araújo, 2012). Desses movimentos multidisciplinares e interdisciplinares resultaram conceitos, definições e noções de gestão social propostas por diferentes autores (Cf. Cançado, 2011; Araújo, 2012; Alcântara, 2015; Guerra, 2015; Garcia, 2016; Persson, 2016; Menon, 2016). Apesar de elementos comuns e convergentes nas conceituações, indicamos que diante da diversidade de conceitos de gestão social é patente o pluralismo e a inexistência de um entendimento único (Justen, Moretto Neto \& Garrido, 2014). Araújo (2012), Alcântara (2015), Garcia (2016) e Menon (2016) também encontraram isso ao revisarem a literatura de gestão social. Para Pinho e Santos (2015), as divergências e polissemias indicam imprecisão conceitual, pois, gera uma falta de identidade: "[...] enveredando, muitas vezes, pela indeterminação, trafegando entre as condições de substantivo, adjetivo, de sujeito e de suporte" (Pinho \& Santos, 2015, p. 4).

Maia (2005, p. 2) contribui apontando para "[...] distintas perspectivas de gestão social" enquanto "[...] construção social e histórica, constitutiva da tensão entre os projetos societários de desenvolvimento em disputa no contexto atual”. Esta questão ainda é marcante no campo, mais de uma década depois em que, revisando os textos de Araújo (2012), Cançado, Pereira e Tenório (2015), Alcântara (2015), Garcia (2016) e Menon (2016), os vestígios de imprecisões, dúvidas e pluralidade de conceitos e práticas ainda estão presentes.

Essas questões nos levam a existência de diferentes abordagens no âmbito da gestão social. Peres Júnior e Pereira (2014) apresentaram quatro: abordagem crítica frankfurteana, abordagem da gestão do desenvolvimento social interorganizacional, abordagem da administração pública societal e abordagem puquiana. $\mathrm{Na}$ abordagem crítica frankfurtiana destaca-se os referenciais de Tenório (1998; 2005) e Cançado, Pereira e Tenório (2013, p. 17) que definem gestão social como: “[...] tomada de decisão coletiva, sem coerção, baseada na inteligibilidade da linguagem, na dialogicidade e no entendimento esclarecido como processo, na transparência, como pressuposto e na emancipação enquanto fim último". Na abordagem da gestão do desenvolvimento social, destacam-se os trabalhos de Fischer e colaboradoras e a gestão social é entendida como: “[...] um ato relacional capaz de dirigir e regular processos por meio da mobilização ampla de atores na tomada de decisão" (Gondim, Fischer \& Melo, 2006, p. 7). A abordagem societal referencia a discussão do modelo societal de Paes de Paula (2005). A abordagem puquiana (denominação referente à Pontifícia Universidade Católica) engloba os trabalhos de alguns autores, tais como Cavalcanti, Raichellis, Cabral, Junqueira e Dowbor (Peres Júnior \& Pereira, 2014). Nessa 
abordagem existem estudos sobre terceiro setor e movimentos sociais, além dos textos sobre valores no espaço público como em Cabral (2011).

É na abordagem puquiana que Peres Junior e Pereira (2014) inserem a perspectiva enfatizada neste estudo: a abordagem normativa da gestão social de Cabral (2008; 2011a; 2011b). Preferimos seguir a denominação de abordagem normativa (e sua autonomia) dada pela própria autora e seus colaboradores, pois ela difere substancialmente, em termos teóricos e metodológicos, dos demais estudos que foram englobados na abordagem puquiana.

Adiante, é importante destacar que a multiplicidade de conceitos revela, e, é efeito das aproximações interdisciplinares da gestão social com diversos domínios do saber, tais como administração, administração pública, serviço social e estudos organizacionais. Tenório (2005) indica a noção de gestão social como administração pública ampliada e Paes de Paula (2005) apresenta a gestão social como forma de gestão do modelo societal de administração pública. Por sua vez, Maia (2005) e Araújo (2012) indicam as discussões presentes no serviço social sobre gestão social e França Filho (2012) defende um diálogo entre gestão social, administração pública e serviço social.

Cançado (2011) e Cançado, Pereira e Tenório (2015, p. 23) entendem a gestão social como "uma área do conhecimento em Administração". Sobre a questão da administração, Guerra e Teodósio (2014) indicam que, apesar das aproximações com a administração, sua natureza parece se configurar mais como híbrida. Acerca dos estudos organizacionais, é Justen (2016, p. 140) que indica: "Gestão social, por certo, tem a interface mais elementar com o campo dos estudos organizacionais". Nisso compartilham temas, referências, debates e perspectivas diversas, especialmente, na linha das influências da teoria da ação comunicativa de Habermas e do debate sobre racionalidade e organizações advindas de Guerreiro Ramos. Além disso, a gestão social vem sendo tratada no Brasil especialmente no "campo de públicas" (Pires et al., 2014). O campo de públicas é um movimento de "busca pela construção de uma agenda [...] unificadora dos diferentes fazeres em torno do ethos republicano, comum às variadas denominações dos cursos que passariam a compor o campo: Administração Pública, Gestão de Políticas Públicas, Gestão Pública, Gestão Social e Políticas Públicas" (Pires et al., 2014, p. 115). Portanto, possui aproximações com a construção da gestão social como área de conhecimento multi e interdisciplinar - voltada para uma gestão democrática e participativa.

Isso tudo reafirma a questão de que a gestão social é um “[...] conhecimento construído por múltiplas disciplinas" (Fischer, 2002, p. 11). Esta revisão nos permite constatar a multiplicidade conceitual enquanto campo de saberes e práticas híbridas. Por isso, optamos por seguir a concepção do campo da gestão social como híbrido de teorias e práticas e que isso não se refere a um processo de banalização, mas a consideração de suas raízes práticas e evidências empíricas. A abordagem normativa da gestão social que resenhamos a seguir destaca, de forma clara, a necessidade de considerar o hibridismo a partir da aplicação no terceiro setor.

\subsection{A abordagem normativa da gestão social e o terceiro setor}

Para tratar da abordagem normativa da gestão social desenvolvida por Cabral (Cabral, 2008; 2011a; 2012; Cabral \& Muzy, 2014), indicamos alguns elementos centrais que justificam o recurso à denominação normativa, por associar-se aos valores e as normas que orientam e referenciam as ações sociais nesse campo: (a) o entendimento da gestão social como reprodutora de valores e produtora de bens públicos, (b) o entendimento do terceiro setor como espaço híbrido, e (c) a discussão sobre valores fundada na crítica à dicotomia fato x valor. Nesse sentido, a designação normativa se distingue de uma abordagem classificatória, reconhecendo a relevância dos valores no entendimento das organizações do terceiro setor: uma organização atua em um espaço público à medida em que persegue valores desse espaço e não apenas por ter algumas características que poderiam individualizá-la. 
Cabral (2008; 2011a) apresenta uma visão do terceiro setor tendo como base Adalbert Evers que busca abranger, de forma plural, os atores e iniciativas relacionadas a esse espaço. Sua abordagem tem embasamento no conceito de mistura de proteção social (welfare mix) que busca tratar o terceiro setor e seus processos "de interações concorrentes e complementares que ocorrem entre os três setores angulares da sociedade: o Estado, o setor mercantil e as comunidades na área do bem-estar" (Cabral, 2011a, p. 49). Cabral (2011a, p. 49) insiste que isso direciona ao entendimento da "coexistência de racionalidades e interesses plurais" a partir do "[...] intercâmbio e do diálogo dessas lógicas e tensões". Cabral (2011b) indica que as muitas nomenclaturas sobre o terceiro setor fazem com que ele seja visto como organizações nãolucrativas, não-governamentais, voluntárias e outras nomenclaturas que desprezam a noção mais profícua de área intermediária das racionalidades do Estado, do mercado e da comunidade.

Cabral (2011a, p. 50) concebe o "[...] Terceiro Setor (TS) como o espaço relacional no qual lógicas diversas, discursos e racionalidades que emergem do Estado, do setor mercantil e da comunidade, são interconectados por um propósito comum de proteção e desenvolvimento sociais". Essa concepção entende o espaço público como "[...] campo de tensões estruturais no qual se debatem as relações, os interesses e as necessidades, as expectativas dos indivíduos que atuam publicamente" (Cabral, 2011a, p. 50). Desse modo, um dos avanços diz respeito a apresentação da "[...] tensão como elemento constitutivo [...]" do terceiro setor (Cabral, 2011a, p. 51).

Essa abordagem inova também em apresentar o conceito de "públicos constituintes" que se articulam no espaço do terceiro setor: instituidores (grupo que instalou a organização), funcionários (desenvolvem atividades como trabalhadores da organização), voluntários (desenvolvem atividades nas organizações de forma autônoma), doadores (contribuem financeiramente) e o público-alvo que são os "[...] beneficiários dos serviços prestados pela organização, ou seja, o cidadão portador de direitos [...] para quem se destinam as ações [...]" (Cabral, 2011a, p. 52). Diante disso, o espaço híbrido do terceiro setor com seus públicos constituintes se constrói com atributos normativos relativos a gestão de bens públicos e reprodução dos valores sociais: representação de interesses coletivos, democratização, controle e defesa social, qualidade, cultura pública, efetividade, sustentabilidade, visibilidade, universalidade e autonomia (Cabral, 2011a). Para a autora, estes são os atributos que dotam o espaço público de uma estrutura valorativa.

Os atributos possibilitam tratar do "[...] processo de gestão social que garanta a reprodução desses valores e a produção dos bens públicos na perspectiva das ENCIR - expectativas, necessidades, capacidade, interesses e representações dos públicos constituintes" (Cabral, 2011a, p. 53). Daí se define a gestão social como reprodutora de valores e produtora de bens públicos. A partir da noção de públicos constituintes, articulados por suas ENCIRs (expectativas, necessidades, capacidade, interesses e representações), é possível identificar empiricamente o hibridismo como manifestação das diversas racionalidades dos atores: "O conceito de públicos constituintes possibilita o reconhecimento dos diversos grupos sociais que se diferenciam pelas ENCIR, associando-se em termos dos valores relevantes que os projetos comunicam" (Cabral; Muzy, 2014, p. 343). Portanto, possibilita a compreensão de diferentes lógicas, bem como as tensões (que pode se tornar conflitos) e os hibridismos.

Essa visão, portanto, não é de um espaço "ideal" ou "consensual" já que nele convivem diferentes interesses e lógicas que podem ser tornar conflituosas, afinal, o terceiro setor se situa em interpelação constitutiva com as comunidades, o setor mercantil e o Estado, e, assim "[...] introjeta uma tensão interna nas próprias organizações" (Cabral, 2011a, p. 54). Em decorrência disso, o entendimento do terceiro setor como área intermediária com as diferentes lógicas, públicos constituintes e ENCIRs orientam um conjunto de fatores determinantes da gestão, que Cabral (2011a) designa como "[...] dualidades da gestão social [...]" das organizações do terceiro setor e que verificou empiricamente (Cabral, 2008; 2011a; 2011b). Dentre as dualidades destacamos: "Equilibrarem apelos solidários e defesas corporativas dos públicos individuais que as constituem", "Proverem bens e serviços para um público-alvo determinado pela missão e atingirem um benefício público que extravasa esse público localizado", "Serem fidedignas (accountable) perante a 
sociedade civil e perante os beneficiários de seus bens em particular" e "Equilibrarem o requisito de controle social sobre o processo de seu desempenho e desenvolverem uma missão autonomamente estabelecida" (Cabral, 2011a, p. 55).

As dualidades são elementos centrais da tensão e do hibridismo que moldam e constituem essas organizações na sua "[...] natureza híbrida e fronteiriça do seu espaço de atuação" (Cabral, 2011a, p. 55). A partir dessa discussão, no que concerne ao nosso objetivo, “[...] a abordagem normativa da gestão social [...] permite contemplar a reprodução dos valores, as ENCIRs e a multiplicidade de determinações oriundas da natureza híbrida e intermediária do Terceiro Setor" (Cabral, 2011a, p. 57). Cabe destacar que, além da abordagem normativa da gestão social acima revisada, são poucas as referências na gestão social sobre a questão dos hibridismos e das tensões Fischer (2012) e Fischer, Melo e Codes (2004) são exceções ao enfatizar a natureza híbrida das interorganizações e Alcântara e Pereira (2017) ao abordarem as tensões.

Por fim, tendo em vista que a gestão de lógicas e espaços híbridos é um "fenômeno" social atual e um tema de pesquisa ainda incipiente - especialmente no campo de estudos e práticas da gestão social, este artigo oferece contribuições interdisciplinares a partir da consideração da busca da cooperação e das evidências dela como uma categoria teórico-empírica posta à coordenação dessas lógicas e espaços.

\section{ALGUMAS BASES TEÓRICAS SOBRE COOPERAÇÃO}

A cooperação pode ser tratada de diferentes formas nas várias áreas do conhecimento. Existem vertentes econômicas, sociais, políticas e naturais, por exemplo. Uma visão geral mostra que o tema não é tratado no campo da gestão social como um elemento substantivo e valorativo. Neste artigo, mostraremos que a cooperação é uma categoria quase "esquecida" pelo campo da gestão social e que os autores desse campo se referem, na maioria das vezes, apenas com generalidade a esse conceito, não permitindo sequer construir um acervo de significados do termo, no que se refere as práticas cooperativas e as concepções epistemológicas e ontológicas com as quais estão tratando da cooperação.

Neste artigo, primeiramente, faremos uma visão de "mapa" tendo como base a economista Elinor Ostrom e o cientista político Robert Axelrod, que tratam substantivamente a cooperação como um valor referido aos processos elementares baseados na reciprocidade. Estes autores mostram, sem necessidade de "idealizar", as relações sociais e as possibilidades de cooperação.

A cooperação, como conceito, pode ser tratada tendo como parâmetro relações elementares dos atores sociais que fazem suas escolhas com base em um referencial de valores, entre os quais a reciprocidade é relevante. Para tanto é preciso reconhecer que a continuidade e permanência desses processos elementares requer que lhes seja atribuída alguma forma de equilíbrio que os fazem duráveis no tempo. Portanto, se os agentes sociais persistem em atuar socialmente, a racionalidade dessa escolha em continuidade impõe a investigação dos mecanismos, também elementares que suportem essa existência continuada em sociedade.

A cooperação entre agentes em processos sociais designa, em primeira aproximação, os esforços conjuntos que identificam congruências parciais de propósitos e se desenvolvem por estratégias nas quais esses entes associam seus objetivos comuns à reciprocidade de resultados. Ring e Van de Ven (1994) oferecem uma estrutura de análise do processo de colaboração, concebida de modo iterativo, o qual, partindo da negociação de expectativas mínimas e congruentes em relação à ação coletiva, viabiliza compromissos parciais que são executados enquanto se aguarda o resultado, ou se incentiva o curso de novas ações. Assim, a cooperação pode ser pensada como um processo de experimentação, ou de tentativas e reformulações subsequentes que dependem de forma recíproca das organizações participantes e dos atores sociais na continuidade ou ampliação de seus compromissos mútuos.

Essa visão dinâmica da cooperação, concebida como processo, sugere que ela evolui à medida que as partes interagem, trocam informação e se conhecem ao longo do tempo, amealhando 
benefícios mútuos e não como forma isolada de altruísmo captado de fontes externas. Axelrod $(1984 ; 1997)$ e Ostrom $(1990 ; 1998)$ valeram-se de resultados da teoria dos jogos e de investigações interdisciplinares e empíricas para fundamentar a cooperação em mecanismos elementares de reciprocidade que conduzem à ação coletiva que alcança com sucesso objetivos em comum, superando as dificuldades sugeridas pela "tragédia dos comuns", investigada por Hardin (1968). Este autor apontava a impossibilidade de cooperação na ação de indivíduos que agissem independentemente e condicionados apenas por seus próprios objetivos, de modo que se tornava uma "tragédia" submeter recursos finitos à exploração coletiva. Tal procedimento indicava, assim, que o individualismo levaria ao fracasso das instituições, organizações e processos - seja no trato com recursos naturais ou outros âmbitos da vida humana. Essa concepção também é próxima a de Mancur Olson (Pereira, Cabral \& Pereira, 2015).

Ostrom (1998), por sua vez, mostrou que a cooperação é mais possível do que previsto por Mancur Olson e Garret Hardin. Axelrod (1984) identificou a reciprocidade em modelos de jogos de "dilema de prisioneiros" acompanhados de interações repetidas, nos quais o surgimento de situações de cooperação independentemente de imposição de moralidade externa. Ostrom (1998) apresentou evidências de populações que apostam na retribuição do outro, tornam possíveis ações coletivas coordenadas por normas, superando assim as dificuldades postas por Hardin (1968).

Essa argumentação estabelece um patamar para a gestão social, na medida em que é por meio da cooperação que se pode regular os compromissos ou se estabelecer os mecanismos de reciprocidade em uma organização ou processos organizativos. Todavia, como alertamos, são poucos textos no campo da gestão social que se atentaram para a questão da cooperação. Alguns pesquisadores citaram brevemente: Teodósio (2008) aponta que todos possuem habilidade em cooperar. Cançado, Villela e Sausen (2016) colocam a cooperação como modus operandi da gestão social - mas, não desenvolvem. Zani e Tenório (2011) e Zani e Tenório (2014) são trabalhos empíricos em que a questão da cooperação aparece, no entanto, é explorada de forma muito breve. Textos bastante citados do campo da gestão social, tais como Paes de Paula (2005), Tenório (1998; 2005), Cançado (2011) e Cançado, Tenório e Pereira (2011), Cançado, Pereira e Tenório (2015), também não enfatizam a problemática da cooperação. Os textos de Dias e Souza (2014), Lampert e Sausen (2008), Ullrich e Carrion (2015) e Villela e Pinto (2009) apresentam a cooperação como relevante para a gestão social e suas práticas, no entanto, sem uma discussão conceitual mais ampla.

Concluímos que as menções sobre a cooperação são passagens rápidas e sem grande desenvolvimento teórico ou empírico no campo da gestão social. É nesta lacuna e no contexto dos hibridismos e das tensões que mostraremos a relevância da cooperação para acadêmicos e praticantes da gestão social.

\section{GESTÃO SOCIAL E TERCEIRO SETOR: TENSÕES, HIBRIDISMOS E COOPERAÇÃO}

Vimos que o conceito de cooperação é pouco lembrado no campo da gestão social. Com base nas discussões sobre gestão social, tensões e hibridismos do terceiro setor e cooperação, apresentamos, nesta seção, três argumentos centrais e complementares deste artigo. É importante lembrar que o hibridismo nos leva a considerar a cooperação, em um sentido amplo, como um fenômeno que envolve a cooperação organizacional, bem como a cooperação intersetorial.

(a) Na perspectiva da gestão social, a cooperação entre as organizações e entre os setores sociais é importante para a coordenação de espaços e lógicas híbridas (que emanam como evidência empírica no caso do Terceiro Setor).

Considerando esse argumento, é importante reconhecer a natureza do apelo ao conceito de hibridismo, sobre o qual repousa a análise do terceiro setor na abordagem de Cabral (2004; 2006; 2008; 2011a). O hibridismo não é uma nomenclatura para escamotear a complexidade deste campo, nem para sugerir algum tipo abstrato de interdependência ou mesmo ambivalência. Muito ao 
contrário, o híbrido deriva da identificação empírica de um conjunto de dualidades da gestão que estão presentes nessas organizações, conforme já apresentadas, que se deparam com problemas práticos decorrentes do espaço onde atuam. Assim, são as dualidades manifestas que indicam o caráter híbrido do espaço intermediário do terceiro setor ao sugerirem que as organizações se defrontam com situações nas quais suas decisões seguem lógicas que se estruturam a partir dos entes - Estado, mercado e comunidades - que comparecem nas fronteiras do espaço social demarcando modos de articulação organizacional tensionados.

Nesse sentido, o hibridismo qualifica a natureza intermediária das relações institucionais, das normas e das relações sociais que se organizam na ação social das organizações e pode ser identificado objetivamente como um atributo que condiciona a gestão. Recentemente, Aimers e Walker (2016) evidenciaram como o hibridismo repercute no desenvolvimento organizacional em organizações sociais da Nova Zelândia, determinando nelas a capacidade de resistirem ou se adaptarem em situações diversas às agendas privadas, públicas e comunitárias que se interceptam em suas ações e são inerentes a elas, porque conectam públicos distintos. Por sua vez, Brandsen e Karré (2011) caracterizaram o hibridismo como recurso de arranjos institucionais heterogêneos.

Quando convocamos para esta análise os valores sociais imanentes a esses processos, podemos referir a natureza híbrida aos sistemas de valores do espaço público (Cabral, 2011b), que orientam a ação social das organizações estabelecendo a coordenação entre lógicas que legitimam os setores privado, público e comunitário, dotados de valores próprios. Tendo em vista que os valores orientam ações, eles comparecem na definição do hibridismo - pois se inter-relacionam com as instituições, as normas e as pessoas, configurando o espaço social para o qual convergem de modos diferentes e tensionados. Esta é uma base para analisar a gestão, que já podemos supor diferenciada, a partir dos processos elementares que se mostram híbridos. De outra forma, o hibridismo não nasce da idealização das organizações e das ações, mas de experiências empíricas (Evers, 1995; Cabral \& Muzy, 2014; Aimers \& Walker, 2016).

Cabral (2011b) destaca que o terceiro setor é um espaço híbrido em que há uma imbricação de fatos-valores. Os valores referidos seriam, portanto, as garantias institucionais a serem observadas na gestão, de maneira coordenada e convergente, conforme solicitado por Luiz Eduardo W. Wanderley (Cf. Cabral, 2011a), para admitir a identidade e a interlocução institucional que as organizações realizam com o Estado, o mercado e a comunidade no espaço intermediário. Como já afirmado, Evers (1995) e Cabral (2011a) mostraram que a gestão tem dualidades, isto é, necessidades institucionais de concatenar lógicas de decisão que podem se contrapor - motivo pelo qual emana também a necessidade da cooperação na coordenação das lógicas diversas. Isso tudo leva a questão das tensões que decorrem do espaço e lógicas híbridas e podem ser testadas empiricamente. Algumas considerações no campo da gestão social, apesar de pouco exploradas, indicam este caminho como promissor.

Alcântara e Pereira (2017), em seu texto, discutem tensões da gestão social que estão presentes nas relações (muitas vezes dicotomizadas no campo) entre Estado e sociedade civil, agir comunicativo e agir estratégico, público e privado, conflito e consenso, dominação e emancipação, entre outras - visões que desprezam que nossa vida ocorre mais in-between do que nos extremos dos elementos apresentados. Essa noção de que a vida ocorre in-between é destacada também no trabalho de Siqueira e Serva (2014) a partir de Guerreiro Ramos. A noção de tensões permite "[...] explorar empiricamente momentos de disputas e cooperação entre as lógicas e ações" (Alcântara \& Pereira, 2017, p. 424). Isso abre discussões para o campo no que se refere aos hibridismos entre mundo-da-vida e sistema nos termos indicados, mas não aprofundado e nem investigado empiricamente por Alcântara e Pereira (2017).

Fischer (2002), Mendonça, Gonçalves-Dias e Junqueira (2012, p. 1393) colocam que “[...] a gestão pressupõe que tensões estarão presentes na construção e desconstrução de lideranças e mandatos, em processos sempre permeados de ambiguidades e contradições". Ou ainda "A gestão do desenvolvimento social é um campo de conhecimento e espaço de práticas marcado pelo hibridismo e a contradição" (Fischer, 2012, p. 117). Fischer (2002) trabalha com as 
interorganizações, no entanto, algumas colocações são pertinentes para nosso espaço do terceiro setor. Para Fischer (2012), as interorganizações têm como características centrais a hibridização ou a complexidade: "As interorganizações são constituídas por organizações diferenciadas, conectadas por propósitos comuns, isto é, integradas" (Fischer, 2012, p. 114). Novamente, isso demanda questões como a cooperação: elas articulam-se "[...] para cooperar e competir, com ações predominantemente sociais ou produtivas" (Fischer, Melo \& Codes, 2004, p. 01). Para outros autores a cooperação emerge como uma condição relevante para o "[...] equilíbrio entre os imbricados e interdependentes interesses" (Cançado, Sausen \& Villela, 2013, p. 86).

Com foco especial na cooperação como valor (a partir de Schwartz e Ostrom), Pereira, Cabral e Pereira (2015) indicam que a cooperação é essencial para os propósitos da gestão social. O texto insiste na ideia da cooperação como atributo valorativo que permite considerá-la na "[...] relação fundamentada na união de esforços e capacidades em prol de interesses e objetivos comuns" (Pereira, Cabral \& Pereira, 2015, p. 114). No entanto, conforme já afirmamos, isso não leva a uma "purificação" e "idealização" das relações sociais e institucionais, pois Fischer (2012, p. 117) lembra que "[...] a cooperação não exclui a competição e a competitividade pressupõe articulações, alianças e pactos" - daí emergir sempre a noção de tensões nos arranjos híbridos. Também se coloca disso que a cooperação enquanto elemento de coordenação não apaga as diferenças. Portanto, os espaços cooperativos não são livres das tensões, dado que são formados por um hibridismo de diferentes (congruentes e divergentes) lógicas. Por isso, na gestão social, Alcântara (2015) usa a noção de tensões buscando superar visões dicotômicas entre racionalidades - pesquisas empíricas sobre a questão das tensões a partir da gestão social permanecem em aberto.

\section{(b) Um campo científico e social marcado pelo hibridismo demanda normativamente o elemento da cooperação nas suas interrelações.}

Tratar da gestão social como campo híbrido de saberes e práticas demanda o entendimento da mesma como interdisciplinar (Maia, 2005; Fischer, 2002; Fischer et al., 2006; Araújo, 2012). Portanto, não é o meio mais produtivo pensar a gestão social como apenas um campo "disciplinar" o que pode levar a ser "monocular" (Justen, Moretto Neto \& Garrido, 2014), mas, explorar a questão da interdisciplinaridade. Sobre essa questão, Menon (2016, p. 160), ao construir a rede de produção científica da gestão social de 2005 a 2015 indica: "[...] o campo da Gestão Social é interdisciplinar, pois congrega pesquisadores com diversas áreas de formação, a saber: administração, sociologia, engenharia de produção, direito etc".

Ao falar da Rede de Pesquisadores em Gestão Social (RGS), Mendonça, Gonçalves-Dias e Junqueira (2012, p. 1395) colocam também o "caráter interdisciplinar da Gestão Social". Citam também que no Encontro Nacional de Pesquisadores em Gestão Social (Enapegs), evento da RGS, “[...] o que prevalece é o saber interdisciplinar, que possibilita criar um discurso, que se situa além das disciplinas particulares" (Mendonça, Gonçalves-Dias \& Junqueira, 2012, p. 1405). Além da rede e do Enapegs, a interdisciplinaridade aparece institucionalizada em diversos elementos do campo como periódico (Revista Interdisciplinar de Gestão Social), tema de evento ("Gestão Social e Interdisciplinaridade: construindo novas pontes e expandindo fronteiras") e diversos grupos de pesquisa (Mendonça, Gonçalves-Dias \& Junqueira, 2012; Guerra, 2015; Menon, 2016).

Argumentando que a gestão social é um campo científico e social marcado pelo hibridismo, recorremos também a Guerra e Teodósio (2015) e Guerra (2015) que apresentaram a gestão social como um campo híbrido de processos de gestão heterogêneos. Guerra e Teodósio (2015) destacam, com ênfase, a noção de que a gestão social é formada por múltiplos saberes. Estes elementos são coerentes com a colocação recente de Guerra (2015) que ilustra isso (Figura 1) a partir do modelo das esferas sociais de Janoski (esfera do Estado, esfera pública, esfera do mercado e esfera privada). Nesse sentido, difere de Cançado, Pereira e Tenório (2015) que tratam da gestão social como própria da esfera pública - esfera pública como locus da gestão social. 


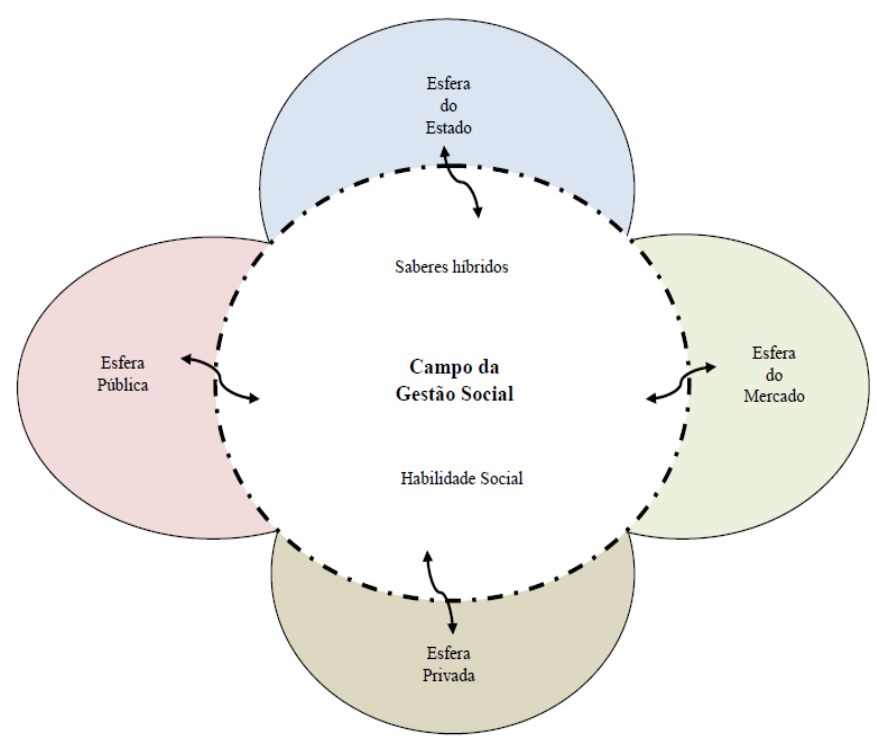

Figura 1: Campos da gestão social

Fonte: Guerra (2015, p. 97)

Os saberes híbridos são "[...] gerados pelos atores sociais tanto no âmbito da universidade quanto na prática da Gestão Social" (Guerra, 2015, p. 24) - considerando "simetria" entre praticantes e acadêmicos. A habilidade social é interpretada a partir de Fligstein como a "[...] capacidade de fazer o outro a cooperar para um fim comum" (Guerra, 2015, p. 24). Portanto, integra nesse processo a questão da cooperação na formação do campo da gestão social. Guerra (2015, p. 200) argumenta que essa discussão “[...] evidencia possibilidades de transformação e ressignificação do campo da Gestão Social ao observar que a produção de conhecimento, mesmo mediada por embates, se baseia em saberes múltiplos e em propósitos que envolvem a noção de coletividade social". Finalmente, segundo Guerra e Teodósio (2015, p. 50), essa "[...] perspectiva aponta uma construção mediada por múltiplos saberes que contribui para a sua pluralidade discursiva e para a constituição de um campo híbrido".

A importância das múltiplas discussões teóricas pode ser referenciada a partir do próprio referencial comum ao campo que é o de Jürgen Habermas (Cf. Cançado, 2011; Alcântara, 2015; Garcia, 2016). Isso pode ser feito tendo como base a ideia de "levar a sério" o que Habermas (1989) chama de "busca cooperativa da verdade". Nesse norte, a cooperação é importante, pois abre caminhos para saberes e conhecimentos pautados pela interdisciplinaridade, pela falibilidade e pela necessidade "[...] do reconhecimento (intersubjetivo) por parte dos leitores, pares e críticos de que a proposta contribui para avanços naquele campo do conhecimento [e/]ou na prática" (Garcia, 2016, p. 235) em um processo contínuo de aprendizagem (Habermas, 1989). Nisso, o autor orienta para:

[...] não nos fixarmos numa única orientação disciplinar e, sim, nos mantermos abertos a diferentes posições metódicas (participante versus observador), a diferentes finalidades teóricas (explicação hermenêutica do sentido e análise conceitual versus descrição e explicação empírica), a diferentes perspectivas de papéis (o do juiz, do político, do legislador, do cliente e do cidadão) e a variados enfoques pragmáticos na pesquisa (hermenêuticas, críticos, analíticos, etc.). (Habermas, 1997, p. 23).

Habermas $(1993 ; 1989 ; 1997)$ foi exemplo ao construir seus "pensamentos" tendo como base diferentes perspectivas, tais como marxismo, pragmatismo, hermenêutica, fenomenologia, funcionalismo, entre outras, e, as áreas da sociologia, filosofia, ciência política, psicologia, antropologia, entre outras. O mais evidente que resulta disso é que orientações interdisciplinares são relevantes em detrimento de apenas uma "[...] teoria monolítica destinada a solucionar todos os problemas vitais" (Habermas, 1993, p. 107). Na gestão social, Alcântara (2015), a partir de Paes de Paula (2013), explora essa questão indicando que a gestão social se fortalece quando se pauta em 
uma comunicação entre diferentes matrizes epistêmicas - isso converge para a cooperação entre diferentes perspectivas. Justen, Moretto Neto e Garrido (2014) também concebem o "essencialismo teórico" como um risco. Os argumentos anteriores (a) e (b) nos permitem, então, concluir que:

\section{(c) A cooperação é essencial em três momentos que se articulam: (1) entre os acadêmicos e os saberes híbridos (Guerra, 2015), tendo em vista o desenvolvimento de um campo científico que valora a cooperação, (2) entre os praticantes, dada a ênfase da gestão social enquanto prática gerencial, e (3) entre acadêmicos e praticantes.}

Para apresentar isso, desenvolvemos a Figura 2 a partir de Fischer (2012) e Guerra (2015). Este modelo emerge da ideia da gestão social como "[...] um campo de conhecimentos e práticas tendo, portanto, dimensões epistemológicas e praxiológicas articuladas" (Fischer, 2012, p. 116). Enquanto domínio de conhecimento, se constrói na interdisciplinaridade (multi, inter e transdisciplinares para Fischer) e enquanto locus de práticas - nos termos de Alcântara (2015) - se experimenta, entre outros, em espaços híbridos (nas interorganizações para Fischer e, para este estudo no terceiro setor). No fim, indicamos, com base em Guerra (2015), que a busca da cooperação ocorre e (se torna importante) tanto para os praticantes quanto para os acadêmicos obviamente como indica o tracejado na Figura 2, estes atores não se excluem - nesse processo, as tensões e os hibridismos se tornam constitutivos em conjunto com elementos, tais como pluralidade, diálogo, heterogeneidade e multiplicidade (ilustrados no centro).

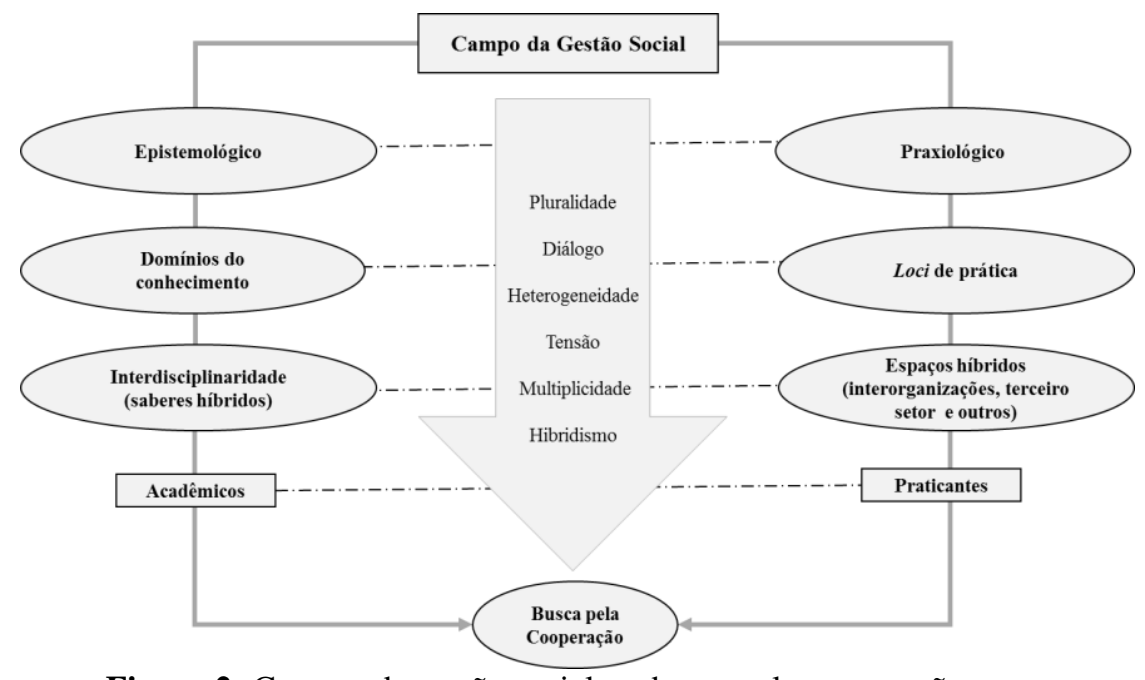

Figura 2: Campos da gestão social e a busca pela cooperação

Fonte: Adaptado e ampliado de Fischer (2012) e Guerra (2015)

A noção de cooperação entre diferentes saberes e a interdisciplinaridade é exemplificada por Boullosa e Schommer (2008) no processo de formação:

A gestão social, pela natureza complexa dos desafios que visa a enfrentar, tanto em relação aos seus fins quanto aos seus meios, exige a articulação multidisciplinar e interdisciplinar da ciência, bem como o reconhecimento, a articulação e o diálogo entre saberes acadêmicos e não acadêmicos. [...] A formação em gestão social deve estar baseada na articulação entre diferentes saberes e tende a ser potencializada em situações que envolvem práticas concretas em torno das quais as pessoas engajam-se, levando saberes que já possuem e construindo outros, coletivamente. Trata-se, pois, de construir processos de formação que valorizem e estimulem a articulação entre diferentes saberes, acadêmicos e não acadêmicos, multi e interdisciplinares, de diferentes atores, com diferentes histórias, origens e áreas de atuação. (Boullosa \& Schommer, 2008, p. 13-14). 
Guerra (2015, p. 87) afirma que é possível “[...] verificar a possibilidade de produção de conhecimento cujos pilares se baseiam na convergência e na cooperação entre os campos, bem como nos distintos poderes que são precedidos de conflitos por se fundarem pela multiplicidade de saberes e de interesses". Tal passagem abre novos entendimentos, tanto para a relação entre acadêmicos, entre praticantes e entre acadêmicos e praticantes. Para Guerra e Teodósio (2014), a natureza híbrida apresenta-se na inserção de perspectivas de outros campos e de outras lógicas. Araújo (2012) constatou empiricamente uma pluralidade de leituras do campo com múltiplos entendimentos, defendendo, com isso, que o hibridismo aparece como elemento constitutivo da gestão social.

Cabe destacar que nossa discussão sobre hibridismo visita o debate de Araújo (2012) sobre ambiguidades na gestão social, apontando caminhos reconstrutivos e interdisciplinares de estudos. Uma saída para a cooperação está dada já que, segundo Araújo (2012, p. 229): "Embora a diversidade do campo seja grande, convive-se de certo modo bem e de modo colaborativo". Assim, Guerra (2015) nos apresenta o cenário "otimista":

A abordagem sobre cooperação permeada pela ideia de sinergia e engajamento entre atores de campos diferentes, além de permitir a universidade trilhar caminhos convergentes com as demandas sociais, contribuiria para a produção de conhecimento sobre Gestão Social apoiada na interação entre diversos atores constituídos de saberes híbridos que, em oposição a especialização de saberes da ciência moderna, incentivaria a auto-reflexividade, a compreensão dos processos que conectam conceitos, proposições e realidades. (Guerra, 2015, p. 95).

Tal cenário pode ser complementado de forma bastante "realista" pela colocação de Fischer et al. (2006, p. 796): “[...] um caráter relacional recíproco, sugere também desequilíbrio e um jogo de forças com momentos de convergência e de antagonismo, de pactos e rupturas. Supõe liberdade e possibilidades de ação e zonas de incerteza que possibilitam recuos e proximidades". Guerra (2015, p. 23) também considera isso, já que apresenta que há disputas que se apoiam em espaços sociais "sobrepostos e híbridos". Por isso, terminamos reconhecendo que a própria defesa da cooperação gera tensões - devendo estar sempre aberta a discussão das relações de poder e disputas diversas dentro do campo da gestão social, ainda mais, estar aberta a experimentação empírica dos valores-fatos a ela relacionados.

\section{CONSIDERAÇÕES PARA UMA AGENDA DE PESQUISA}

Vimos na argumentação apresentada que a "cooperação" se estabelece como uma categoria teórico-empírica e pode ser considerada como um mecanismo de coordenação entre as lógicas que se apresentam no espaço híbrido intermediário, no qual atuam as organizações do terceiro setor e no campo de estudos e práticas da gestão social. Decorre também que essa abordagem da gestão social reconhece a relevância dos valores, permite contemplar a cooperação e a reciprocidade como valores, que de modo coordenado e convergente, se manifestam nessa gestão peculiar. Ficou mostrado ainda que o hibridismo não é elemento que desfigura a "identidade" do gestor social, mas, pelo contrário, que o molda e o torna capaz de coordenar no espaço intermediário as diferentes lógicas e suas tensões. Antes de nós, Fischer (2012) colocou que os gestores sociais precisam atuar nos nós e conexões. Argumentamos também que a cooperação é essencial entre os acadêmicos e os saberes híbridos, tendo em vista o desenvolvimento de um campo científico que valora a cooperação, quanto entre os praticantes dado a ênfase da gestão social enquanto prática gerencial e entre praticantes e acadêmicos.

É razoável pretender que esses valores que trazemos aqui (portanto, também a cooperação) sejam investigados experimentalmente e que se identifiquem suas manifestações, assim, como foram aqueles que nortearam as contribuições de Cabral (2008; 2011a; 2011b), para que se estabeleçam as bases empíricas da gestão de acordo com a abordagem normativa. Isto significa 
identificar dualidades as quais o gestor se submete para a coordenação de suas atividades no espaço intermediário de atuação - e como a cooperação se constrói nessas inter-relações. Essas questões indicariam as estratégias validadas socialmente e justificadas na organização para o estabelecimento da cooperação. Este é um início da nossa agenda de pesquisa.

Outra linha de pesquisa diz respeito a investigações que associem abordagens empíricas e exame mais detalhado das contribuições teóricas para a aplicação em aspectos da gestão, como é o caso das teorias de avaliação. É importante lembrar que os modos convergentes e coordenados de justaposição ou sopesamento dos valores sugere que a cooperação seja examinada também e necessariamente ao lado de outros atributos. Ainda, pesquisar se a cooperação comunica à gestão um ingrediente de realização prática que pode estar associado à valorização da autonomia nos empreendimentos cooperativos e práticas de cooperação. Os resultados de Aimers e Walker (2016) permitem inferir que a cooperação possui essa decorrência e justificam o interesse de investigar, entre nós, esse fenômeno.

É importante ressaltar que a abordagem sugere essa manifestação e o ambiente (híbrido e permeado de tensões) ideal para investigá-la, por solicitar explicitamente a apreciação do sopesamento dos valores. De outra forma, se uma abordagem da gestão social insistir na valorização unilateral da participação, por exemplo, e a identifique como elemento primordial dos processos de gestão, pode, na prática, descuidar do valor autonomia ou de outros valores. De outra forma, essa abordagem existe, desde o início, no valor da pluralidade no campo da gestão e das organizações in foco. Portanto, existe no hibridismo de saberes, práticas e lógicas aqui destacadas e não em processos de "purificação" que apresente poucas categorias como explicativas deste campo híbrido. Ainda, caso se insista na prevalência, por exemplo, da autonomia como valor preponderante, podese recair no engano das formas ingênuas de comunistarismo, que é a outra face da desconsideração do hibridismo. De toda forma, é na gestão e nas suas dualidades (portanto, também na tensão para além de somente deliberação consensual) que se pode identificar o processo de sopesamento dos valores que determina as escolhas sociais e se constitui na realização do hibridismo. Este é o sentido da coordenação e convergência do recurso aos valores-fatos que precisa ser verificada empiricamente.

Adiante, a partir da vida cotidiana dos atores sociais, uma agenda de pesquisa se desenvolve conforme a busca pela compreensão de como os praticantes e acadêmicos lidam com os hibridismos e as tensões - o que pode ser feito especialmente a partir de estudos qualitativos, com entrevistas em profundidade, grupo focal e história de vida. Finalmente, as relações entre cooperação, reciprocidade e solidariedade podem ser testadas e, para tanto, pode-se levantar a "teoria da dádiva" que nos aproximaria de autores, tais como Paulo Martins, Alain Caillé e Jacques Godbout. Destacamos que, em outra ocasião, é possível procedimentos que busquem identificar em que medida a cooperação está pressuposta implicitamente em vários estudos da gestão social - o que pode ser feito por meio da noção de "reconstrução" de Habermas (1989), todavia, neste estudo optamos por entender as discussões manifestas do campo à "cooperação", afinal, isso também revelou ênfases teóricas e conceituais.

Finalmente, como argumentado, a questão da interdisciplinaridade precisa ser debatida, já que aqui entendemos o campo da gestão social como "[...] área interdisciplinar de conhecimento e atuação" (Guerra, 2015, p. 30) e que busca "[...] aprofundar diálogos interdisciplinares" (Araújo, 2012, p. 220). Steinmetz (2017) argumenta que a interdisciplinaridade é motivada por problemas acadêmicos, interesses e batalhas específicas dos campos. É importante destacar que a interdisciplinariedade não dilui a noção de "fronteiras", daí, este autor usar o termo "campos científicos semiautônomos" que também se abre como possibilidade de discussão no âmbito da gestão social. Por fim, vale a passagem de Fiorin (2008, p. 52) no que tange as possibilidades e dificuldades da interdisciplinaridade: “[...] seria preciso disposição para mudar hábitos intelectuais, respeito pela diferença, abertura para a alteridade, vontade de abandonar a comodidade de trilhar os sendeiros já batidos. Seria necessário olhar para nossos vizinhos de sala sem desprezo [...]" esperamos cooperar por meio deste artigo. 


\section{REFERÊNCIAS}

Aimers, J., \& Walker, P. (2016). Resisting hybridity in community-based third sector organisations in aotearoa New Zealand. Voluntas: International Journal of Voluntary and Nonprofit Organizations, 27(6), 2666-2684.

Alcântara, V. C. (2015). Mundo-da-vida e sistema: o locus da gestão social sob a abordagem habermasiana. (Dissertação de mestrado). Universidade Federal de Lavras, Lavras, Brasil.

Alcântara, V. C., \& Pereira, J. R. (2017). O locus da gestão social no contexto das inter-relações e tensões entre mundo-da-vida (lebenswelt) e sistema (system). Organizações \& Sociedade, 24(82), 412-431.

Alves, M. A. (2002). Terceiro setor: o dialogismo polêmico. (Tese de doutorado em Administração de Empresas). Fundação Getúlio Vargas, SP, Brasil.

Araújo, E. T. (2012). (In) consistências da gestão social e seus processos de formação: um campo em construção. (Tese de doutorado). Pontifícia Universidade Católica de São Paulo, SP, Brasil.

Axelrod, R. M. (1984). The evolution of cooperation. Princeton: Princeton University Press.

Axelrod, R. M. (1997). The complexity of cooperation: agent-based models of competition and collaboration. Princeton, NJ: Princeton University Press.

Boullosa, R. D. F., \& Schommer, P. C. (2008). Limites da natureza da inovação ou qual o futuro da gestão social. Encontro da Anpad, 32.

Brandsen, T., \& Karré, P. M. (2011). Hybrid organizations: no cause for concern? International Journal of Public Administration, 34(13), 827-836.

Cabral, E. H. S. (2008). A gestão social do terceiro setor e suas dualidades. Administração em Diálogo, 11(2), 21-34.

Cabral, E. H. S. (2011a). Uma abordagem normativa para a gestão social no espaço público. In: Pereira, J. R. et al. Gestão social e gestão pública: interfaces e delimitações. Lavras: Ufla, 47-58.

Cabral, E. H. S. (2011b). Valores e espaço público: referenciais e instrumentos para a avaliação de projetos sociais. Revista de Administração Pública, 45(2), 1915-1941.

Cabral, E. H. S., \& Muzy, P. T. (2014). Os valores e o valor da moeda: hipóteses sobre a comensurabilidade e a monetarização do impacto de projetos sociais. Cadernos Ebape.BR, 12(2), 339-356.

Cançado, A. C. (2011). Fundamentos teóricos da gestão social. (Tese de doutorado). Universidade Federal de Lavras, Lavras, MG, Brasil.

Cançado, A. C., Pereira, J. R., \& Tenório, F. G. (2015). Gestão social: epistemologia de um paradigma (2 $2^{\mathrm{a}}$ ed.). Curitiba: Editora CRV.

Cançado, A. C., Tenório F. G., \& Pereira, J. R. (2011). Gestão social: reflexões teóricas e conceituais. Cadernos Ebape.BR, 9(3), 681-703.

Cançado, A. C., Villela, L. E., \& Sausen, J. O. (2016). Gestão social e gestão estratégica: reflexões sobre as diferenças e aproximações de conceitos. Revista de Gestão Social e Ambiental, 10(3), 6984.

Dias, T. F., \& de Souza, W. J. (2014). Gestão social e economia solidária: o caso da associação dos produtores e produtoras rurais da feira agroecológica de Mossoró-Aprofam, Mossoró-RN. Teoria e Prática em Administração, 4(1), 261-294. 
Evers, A. (1995). Part of the welfare mix: The third sector as an intermediate area. Voluntas: International Journal of Voluntary and Nonprofit Organizations, 6(2), 159-182.

Fiorin, J. L. (2008). Linguagem e interdisciplinaridade. Alea: Estudos neolatinos, 10(1), 29-53.

Fischer, T. (2012). Gestão social do desenvolvimento de territórios. Revista Psicologia, Organizações e Trabalho, 12(1), 113-119.

Fischer, T., Melo, V. P., \& Codes, A. L. (2004). Integração e gestão do desenvolvimento sócioterritorial: um estudo de organizações da sociedade civil em municípios baianos. Encontro da Anpad, 27.

Fischer, T., Melo, V. P., Carvalho, M. R. D., Jesus, A. D., Andrade, R. A., \& Waiandt, C. (2006). Perfis visíveis na gestão social do desenvolvimento. Revista de Administração Pública, 40(5), 789808.

França Filho, G. C. (2012). Gestão Social entre a administração pública e o serviço social: um diálogo necessário. In: Junqueira, L. A. P., Gonçalves-Dias, S. F. F., Wanderley, M. B., \& Mendonça, P. Gestão social: mobilizações e conexões. São Paulo: Lcte Editora, 105-110.

Garcia, A. S. (2016). Esferas públicas como categoria fundante da gestão social. (Dissertação de mestrado). Universidade Federal de Lavras, Lavras, MG, Brasil.

Guerra, J. F. C. (2015). A produção de conhecimento sobre Gestão Social: um estudo da relação entre academia e praticantes. (Tese de doutorado em Administração). Pontifícia Universidade Católica de Minas Gerais, Belo Horizonte, MG, Brasil.

Guerra, J. F. C., \& Teodósio, A. S. S. (2014). Gestão social: aspectos que a aproxima dos domínios da administração. Reuna, 19(3), 49-64.

Guerra, J. F. C., \& Teodósio, A. S. S. (2015). Dialogismo e reflexividade: uma análise da contribuição dos centros e programas de estudos de Gestão Social no Brasil. Revista de Ciências da Administração, 17(ed. esp.), 45-62.

Habermas, J. (1989). Consciência moral e agir comunicativo. Rio de Janeiro: Tempo Brasileiro.

Habermas, J. (1993). Passado como futuro. Rio de Janeiro: Tempo Brasileiro.

Habermas, J. (1997). Direito e democracia: entre facticidade e validade. Rio de Janeiro: Tempo Brasileiro.

Hardin, G. (1968). The tragedy of the commons. Science, 162(3859), 1243-1248.

Junior, S. S., Paixão, G. D. J., Meller, A. J., \& Neto, L. M. (2014). O legado do pensamento de Alberto Guerreiro ramos para a gestão social. Revista Gestão Organizacional, 7(3), 47-60.

Justen, C. E. (2016). O Angelus Novus emoldurado à gestão social - reflexões acerca da construção de políticas públicas emancipadoras. Desenvolvimento em Questão, 14(36), 135-157.

Justen, C. E., Moretto Neto, L., \& Garrido, P. (2014). O. Para além da dupla consciência: Gestão Social e as antessalas epistemológicas. Cadernos Ebape.BR, 12(2), 237-251.

Lampert, A. L., \& Sausen, J. O. (2008). Gestão social na relação interorganizacional de instituições filantrópicas: um estudo em hospitais da Rede Hospinoroeste/RS. Desenvolvimento em Questão, 6(12), 87-1198.

Maia, M. (2005). Gestão Social - Reconhecendo e construindo referenciais. Textos \& Contextos, 4 , $1-18$.

Mendonça, P. M. E., Gonçalves-Dias, S. L. F., \& Junqueira, L. A. P. (2012). Gestão social: notícias sobre o campo de estudos e práticas a partir das interações e debates do Enapegs, 6. Revista de Administração Pública, 46(5), 1391-1408. 
Meneghetti, F. K. (2011). Tréplica - O que é um Ensaio-Teórico? Revista de Administração Contemporânea,15(2), 343-348.

Menon, I. O. (2016). Gestão Social como campo do saber no Brasil: uma análise de sua produção científica pela modelagem de redes sociais (2005-2015). (Dissertação de mestrado). Universidade de São Paulo, São Paulo, SP, Brasil.

Ostrom, E. (1990). Governing the commons: the evolution of institutions for collective action. Cambridge: Cambridge University Press.

Ostrom, E. (1998). A behavioral approach to the rational choice theory of collective action. American Political Science Review, 92(1), 1-22.

Paes de Paula, A. P. (2005). Por uma nova gestão pública: limites e potencialidades da experiência contemporânea. Rio de Janeiro: FGV.

Paes de Paula, A. P. (2013). Abordagem freudo-frankfurtiana, pesquisa-ação e socioanálise: uma proposta alternativa para os estudos organizacionais. Cadernos Ebape.BR, 11(4), 543-555.

Pereira, J. R., Cabral, E. H. S, \& Pereira, J. R. (2015). Gestão social e governing the commons: a cooperação como elo de convergência. Revista de Ciências da Administração, 17(43), 112.

Peres Junior, M. R., \& Pereira, J. R. (2014). Abordagens teóricas da gestão social: uma análise de citações exploratórias. Cadernos Ebape.BR, 12(4), 221-236.

Persson, E. (2016). Burocracia, ideologia e gestão social: uma abordagem crítica à luz da categoria habermasiana da esfera pública. 353 p. (Dissertação de mestrado). Universidade Federal de Santa Catarina, Florianópolis, SC.

Pinho, J. A. G., \& Santos, M. E. P. (2015b). Aporias em torno do conceito de Gestão Social: dilemas teóricos e políticos. Rege - Revista de Gestão, 22(2), 155-172.

Pires, V. et al. (2014). Dossiê-campo de públicas no Brasil: definição, movimento constitutivo e desafios atuais. Administração Pública e Gestão Social, 6(3), 110-126.

Ring, P. S., \& Van de Ven, A. H. (1994). Developmental processes of cooperative interorganizational relationships. Academy of Management Review, 19(1), 90-118.

Rorty, R. Verdade, universalidade e política democrática (justificação, contexto, racionalidade e pragmatismo). In Souza, J. C. (2005). Filosofia, racionalidade, democracia: os debates Rorty \& Habermas. São Paulo: Editora Unesp, 103-162.

Siqueira, G., \& Serva, M. (2014). Tensão entre racionalidades na abordagem substantiva das organizações. In: Colóquio internacional de epistemologia e sociologia da ciência da administração, 4, Florianópolis.

Steinmetz, G. (2017). Field theory and interdisciplinarity: history and sociology in Germany and France during the Twentieth Century. Comparative Studies in Society and History, 59(2), 477-514.

Tenório, F. G. (1998). Gestão social: uma perspectiva conceitual. Revista de Administração Pública, 32(5), 7-23.

Tenório, F. G. (2005). (Re)visitando o conceito de gestão social. Desenvolvimento em Questão, $3(2), 101-124$.

Teodósio, A. S. S. (2008). Parcerias tri-setoriais na esfera pública: perspectivas, impasses e armadilhas para a modernização da gestão social no Brasil. (Tese de Doutorado em Administração). Fundação Getúlio Vargas, Rio de Janeiro, RJ, Brasil.

Ullrich, D., \& Carrion, R. (2015). Gestão da cooperação internacional para o desenvolvimento sulsul à luz dos postulados e princípios da gestão social. Caderno $C R H, 28(75), 657-669$. 
Villela, L. E., \& Pinto, M. C. S. (2009). Governança e gestão social em redes empresariais: análise de três arranjos produtivos locais (APLs) de confecções no estado do Rio de Janeiro. Revista de Administração Pública-RAP, 43(5), 1067-1089.

Zani, F. B., \& Tenório, F. G. (2011). Gestão social do desenvolvimento: a exclusão dos representantes dos empresários? O caso do Programa Territórios da Cidadania Norte-RJ. Cadernos Ebape.BR, 3(9), 783-802.

Zani, F. B., \& Tenório, F. G. (2014). Gestão social do desenvolvimento: o desafio da articulação de atores sociais no Programa Territórios da Cidadania Norte-RJ. Organizações \& Sociedade, 21(68), 853-874.

Data da submissão: 25/05/2017

Data de aceite: 06/12/2017 